\title{
Treatment of hepatocellular carcinoma with major portal vein thrombosis by combined therapy with subcutaneous interferon- $\alpha$ and intra-arterial 5-fluorouracil; role of type I interferon receptor expression
}

\author{
H Ota', H Nagano*,', M Sakon', H Eguchi', M Kondo', T Yamamoto', M Nakamura', B Damdinsuren', \\ H Wada', S Marubashi', A Miyamoto', K Dono', K Umeshita', S Nakamori', K Wakasa ${ }^{2}$ and M Monden' \\ 'Department of Surgery and Clinical Oncology, Graduate School of Medicine, Osaka University, 2-2, Yamadaoka E-2, Suita, Osaka 565-087I, Japan; \\ ${ }^{2}$ Department of Pathology, Osaka City University Hospital, I-5-7, Asahi-cho Abeno-ku, Osaka 545-005 I, Osaka, Japan
}

\begin{abstract}
We previously reported the beneficial effects of combination therapy of interferon (IFN)- $\alpha / 5$-fluorouracil (FU) for advanced hepatocellular carcinoma (HCC) with tumour thrombi in the major portal branches. This report describes the results of longer follow-up and includes more than double the number of patients relative to the original report, and evaluates the role of IFN- $\alpha /$ type 2 interferon receptor (IFNAR2) expression on the response to the combination therapy. The study subjects were 55 patients with advanced HCC and tumour thrombi in the major branches of the portal vein ( $\mathrm{Vp} 3$ or 4 ). They were treated with at least two courses of IFN- $\alpha / 5$-FU without major complication. In the 55 patients, 24 (43.6\%) showed objective response (eight (I4.5\%) showed complete response, 16 (29.1\%) partial response), four (7.3\%) showed no response, and 27 (49.1\%) showed progressive disease. Immunohistochemically, IFNAR2 expression was detected in nine out of 13 (69.2\%) patients. There was significant difference in the time-to-progression survival $(P=0.0002)$ and the overall survival $(P<0.000 \mathrm{I})$ between IFNAR2-positive and -negative cases. There was a significant correlation between IFNAR2 expression and response to IFN- $\alpha / 5$-FU combination therapy in univariate analysis $(P=0.0070)$. IFN- $\alpha / 5-F U$ combination therapy is a promising modality for advanced HCC with tumour thrombi in the major portal branches and could significantly depend on IFNAR2 expression.

British Journal of Cancer (2005) 93, 557-564. doi: I0.1038/sj.bjc.6602742 www.bjcancer.com

Published online 16 August 2005

(c) 2005 Cancer Research UK
\end{abstract}

Keywords: hepatocellular carcinoma; IFNAR2; portal vein thrombosis; arterial infusion chemotherapy

The prognosis of patients with advanced hepatocellular carcinoma (HCC) remains poor, particularly in patients with tumour thrombi in the major branches of the portal vein ( $\mathrm{Vp} 3$ or $\mathrm{Vp} 4$ ) (Chen et al, 1994; Yen et al, 1995; Tanaka et al, 1996; Ando et al, 1997; Furuse et al, 1997; Lee et al, 1997; CLIP investigators, 1998; Asahara et al, 1999; Yamakado et al, 1999). Almost all patients with unresectable tumours die within several months and have poor quality of life (QOL) due to intractable ascites or oesophageal bleeding. Even in patients with resectable HCC, the prognosis is extremely poor despite aggressive surgery (Tanaka et al, 1996; Asahara et al, 1999). In such a situation, conventional therapies like percutaneous ethanol injection, microwave coagulation therapy, and transcatheter arterial embolisation generally have no clinical effect on HCC with portal tumour thrombi due to poor efficacy and possible complications (Chen et al, 1994; Yen et al, 1995; Furuse et al, 1997). Furthermore, arterial infusion

*Correspondence: Dr H Nagano;

E-mail: hnagano@surg2.med.osaka-u.ac.jp

Received I 4 February 2005; revised I June 2005; accepted I 3 July 2005; published online 16 August 2005 chemotherapy has also been attempted, but its effectiveness is still unsatisfactory (Doci et al, 1988; Ando et al, 1997). Therefore, a new strategy is required for these patients with intractable HCC and tumour thrombi in the major branch of the portal vein.

Several recent studies have indicated the beneficial effects of interferon (IFN)- $\alpha$-based combination therapies for hepatomas. Patt et al (1993) reported $31 \%$ response rate in patients with unresectable advanced hepatoma and low alpha-fetoprotein (AFP) levels. Using intra-arterial infusion chemotherapy and systemic IFN- $\alpha$, Urabe et al (1998) reported a response rate of $47 \%$ in patients with Vp3. In another study, Leung et al (1999) used cisplatin, doxorubicin, and IFN- $\alpha$ and reported that this treatment converted nine patients of 36 patients with inoperable HCC to become suitable for tumour resection, and none developed postoperative recurrence. More recently, Chung et al (2000) reported partial response in 33\% (six out of 18) of their patients with major portal vein thrombosis or distant metastases, who received systemic combination therapy with IFN- $\alpha$ and cisplatin (CDDP). Based on this background, we experienced a patient with advanced HCC and lung metastasis, who was successfully treated with a combination therapy of IFN- $\alpha$ and tegafur/uracil (UFT) 
(Miyamoto et al, 2000). In addition, we recently reported the outstanding effects of intra-arterial 5-fluorouracil (5-FU) combined with subcutaneous IFN- $\alpha$ for advanced HCC with tumour thrombi in the major portal branches, since 1997 (Sakon et al, 2002). Based on our results, the marked effects and acceptable toxicity of our therapy in HCC patients with extremely poor prognosis suggest that IFN- $\alpha / 5-\mathrm{FU}$ combination therapy is a promising treatment regimen.

However, the response rate in the above studies was not absolute; to advance the effect of IFN- $\alpha / 5-\mathrm{FU}$ combination therapy and to increase the response rate, it is necessary to investigate the mechanism and to predict the response to IFN- $\alpha / 5$-FU combination therapy, for patients with advanced HCC. Interferon- $\alpha$ suppresses the proliferation of all type I interferon receptor 2 (IFNAR2)-positive cancer cell lines in vitro through mechanisms related to apoptosis or inhibition of cell cycle. Furthermore, the antineoplastic effects of IFN- $\alpha$ may be mediated through its high-affinity membrane type I receptor, IFNAR2. Thus, IFNAR2 expression in HCC tissues may be a useful predictor of the response to IFN- $\alpha / 5-\mathrm{FU}$ combination therapy.

The present study is an extension to our previous work (Sakon et $a l, 2002)$, in which we examined the clinical effects of the combination therapy of subcutaneous IFN- $\alpha$ and arterial infusion of 5-FU in 55 patients with HCC associated with Vp3 and investigated whether the response to such therapy is influenced by the expression level of IFNAR2.

\section{MATERIALS AND METHODS}

\section{Patients and selection criteria}

This was a single arm open label study, based on our pervious report (Sakon et al, 2002). Between December 1997 and December 2003, 124 patients with advanced HCC and tumour thrombi in the major branches of the portal vein and multiple liver metastasis (Vp3 or 4, IM3) were diagnosed in our department. Among these patients, 10 were excluded because of liver failure, 44 underwent hepatectomy before IFN- $\alpha / 5$-FU combination therapy because they were within the indications for operation, 15 received other treatments, seven had distant metastases, four were over 75 years of age, and four patients refused to sign the informed consent form because of fear of adverse effects. The remaining 55 patients were enrolled in the study. All patients were radiologically confirmed to have tumour thrombi in the major branches of the portal vein (Vp3 or 4), and multiple intrahepatic metastases (IM3). The diagnosis was based on liver function tests, serum alphafetoprotein (AFP), serum protein induced by vitamin $\mathrm{K}$ absence or antagonist-II (PIVKA-II) and imaging techniques including computed tomography (CT) scan, magnetic resonance imaging (MRI), hepatic angiography and arterial portography. The final diagnosis was unresectable HCC in 55 patients mainly because of marked portal tumour thrombi extending into all the three major branches and/or poor liver function. Among the 55 patients, 13 signed informed consent documents approved by the institutional review board attesting to the fact that they were aware of the investigative nature of the study. Therefore, liver biopsy could be performed in these 13 patients. On the other hand, the remaining 42 patients did not sign informed consent documents because of fear of tumour implantation and/or bleeding accompanying liver biopsy.

The following were the eligibility criteria for selection for intraarterial combination therapy; (1) age of more than 20 years and less than 75 years, (2) tumour thrombi invading at least one of the main branches of the portal vein, (3) presence of multiple intrahepatic metastases in more than three segments (IM3), (4) absence of extrahepatic metastases, (5) a granulocyte count of more than $2500 \mu \mathrm{l}^{-\mathrm{f}}$ and less than $12000 \mu \mathrm{l}^{-\mathrm{T}}$, (6) a red blood cell count of more than $8.0 \mathrm{~g} \mathrm{dl}^{-1}$, (7) a platelet count exceeding
$8 \times 10^{4} \mu \mathrm{l}^{-1}$, (8) GOT and GPT of less than $100 \mathrm{IUl}^{-1}$. (9) total bilirubin less than $1.4 \mathrm{~g} \mathrm{dl}^{-1}$, (10) serum BUN less than $30 \mathrm{mg} \mathrm{dl}^{-1}$, (11) serum creatinine less than $1.5 \mathrm{mg} \mathrm{dl}^{-1}$, (12) successful implantation of intra-arterial catheter and drug delivery system, and (13) a performance status of level 0-2 (Eastern Cooperative Oncology Group, ECOG). These eligibility criteria were based on our previous report (Sakon et al, 2002). All patients signed informed consent documents approved by the institutional review board attesting to the fact that they were aware of the investigational nature of the study and were willing to try the combination therapy.

\section{Treatment protocol}

In each of our 55 patients, an intra-arterial catheter was inserted through the subclavian or femoral artery with a subcutaneously implanted drug delivery system (Toyoda et al, 1995). Each patient was treated with subcutaneous IFN- $\alpha$ (OIF, Otsuka Pharmaceutical Co., Tokushima, Japan) and intra-arterial infusion of 5-FU (Kyowa Hakko Co., Tokyo). Interferon- $\alpha\left(5 \times 10^{6}\right.$ U (5 MU)) was administered on days 1,3 , and 5 of each week. Continuous infusion chemotherapy (5-FU, $300 \mathrm{mg} \mathrm{m}^{-2}$ day $^{-1}$ ) through the proper hepatic artery was performed every 2 weeks for two sessions via a catheter connected to a subcutaneously implanted drug delivery system. In summary, 55 patients received this therapy for multiple HCCs with tumour thrombi in the main branch of the portal vein. There was no dose escalation, because none of the six patients, in whom the adverse effects reached level 2 of the ECOG classification, were there (with the exception of platelet and leukocyte counts of $<0.4 \times 10^{5} \mu \mathrm{l}^{-1}$ and $2000 \mu \mathrm{l}^{-1}$, respectively, before treatment because of cirrhosis).

\section{Evaluation of response to anticancer therapy}

In addition to serum chemistry, tumour markers such as AFP and PIVKA-II were measured at least once every 4 weeks. Abdominal CT scan or dynamic MRI was also performed before and after treatment, and once every 3 months thereafter. We evaluated the effects of therapy at 3 months after the commencement of this therapy. Simon's two-stage design (WHO handbook, 1979) was used to calculate the sample size for clinical response evaluation. The objective response was classified according to the ECOG criteria (Oken et al, 1982). Complete response (CR) was defined as the normalisation of tumour markers and the disappearance of all tumours and portal vein thrombosis on CT and/or MRI. Partial response (PR) represented a decrease of tumour markers and 50$99 \%$ regression on the two-dimensional measurement. No change (NC) represented less than $50 \%$ regression or less than $25 \%$ progression. Progressive disease (PD) represented more than $25 \%$ progression. This classification was based on the World Health Organization (WHO) handbook (WHO handbook, 1979).

\section{Reagents}

Rabbit polyclonal anti-human IFNAR2 antibody (OCT4813, Otsuka Pharmaceutical Co., Tokushima) and its blocking peptide were prepared according to the report by Novick et al (1994).

\section{Immunohistochemistry}

The expression of IFNAR2 was examined in 13 tumour samples of 55 cases by immunohistochemistry (Figures 3, 4 and 5, Table 3 ). Biopsy samples were obtained with a needle guide/cover kit and a 16-gauge core tissue biopsy needle (Bard MAGNUM: C.R. Bard Inc., Covington, USA) under colour Doppler ultrasonography. Immunohistochemistry was carried out according to the method described previously by our laboratories (Kondo et al, 2000). Tissue sections $(4-\mu \mathrm{m}$ thick) were deparaffinised in xylene and 
heat antigen retrieval was performed as described previously (Ciaparrone et al, 1998). The slides were then processed for immunohistochemistry on the TeckMate Horizon automated staining system (Dako Corporation, Carpinteria, CA), using the EnVision + peroxidase kit (DAKO, Glostrup, Denmark). In the step of primary antibody reaction, the slides were incubated with the IFNAR2 antibody (final concentration: $2.5 \mathrm{mg} \mathrm{ml}^{-1}$ ) for $1 \mathrm{~h}$ at room temperature. For negative controls, nonimmunised rabbit IgG (Vector Laboratories, Burlingame, CA, USA) or TBS (Tris-buffered saline) was used as a substitute for the primary antibody to verify the possibility of false positive responses from nonspecific binding of IgG or from the secondary antibody. In addition, absorption tests were performed on tissue sections. The intensity of IFNAR2 was scored in a scale from 0 to 2 . IFN- $\alpha$ /type 2 interferon receptor expression was often heterogeneous. The histological or immunohistological type that constituted the major volume of the tumour was selected as the representative type. Staining was repeated at least twice to avoid possible technical errors but basically identical results were obtained. All slides were interpreted by one of two investigators ( $\mathrm{HO}$ or $\mathrm{MK}$ ) in a blinded manner without knowledge of the clinical and pathological parameters. When the initial diagnosis was different, the final diagnosis was mutually determined using a multihead microscope by two investigators ( $\mathrm{HO}$ or $\mathrm{MK}$ and $\mathrm{KW}$ ).

\section{Statistical analysis}

The Breslow-Gehan-Wilcoxon univariate test was used to examine the possible relationship between the effect of therapy (CR, PR vs NC, PD), Child - Pugh score, serum AFP, serum PIVKAII, Okuda score, CLIP score (CLIP investigators, 1998) and the expression of IFNAR2. Survival curves were constructed using the Kaplan-Meier method. Differences in distribution between groups were compared by the $\chi^{2}$ test and differences in mean values by the Student's $t$-test. All data were expressed as mean \pm s.e.m. A $P$-value less than 0.05 denoted the presence of a statistically significant difference.

\section{RESULTS}

\section{Patient characteristics}

Between 1997 and 2003, 55 patients who had HCC with tumour thrombi in the major branches of portal vein were enrolled in this study. The clinical characteristics of the study participants are summarized in Table 1. The median age of patients was 58.2 years. In total, 24 patients were positive for HBV (anti-HBs antigen), while 29 were positive for $\mathrm{HCV}$ (anti-HCV antibody) and five patients were negative for both $\mathrm{HBV}$ and HCV. The mean granulocyte count was $5310 \mu \mathrm{l}^{-1}$, the mean platelet count was $15.3 \times 10^{4} \mu l^{-1}$. Almost all cases were Child A or B. Alphafetoprotein and/or PIVKA-II were abnormal in 52 of 55 cases. The median tumour size was $6.4 \mathrm{~cm}$.

\section{Clinical response to combination therapy}

In this study, 55 patients with unresectable HCCs completed at least two cycles of IFN- $\alpha / 5$-FU combination therapy, with a mean number of treatment cycles of 3.6 cycles (range, $2-12$ cycles). With respect to time-to-progression, the median progression-free survival period was 5.2 months and the 1-, 2-, 3- and 5-year progression-free survival rates were $11.3,3.8,3.8$, and $1.9 \%$, respectively. Furthermore, the median overall survival period was 11.8 months and the 1-, 2-, 3- and 5-year survival rates were 48.9, $28.8,16.4$, and $16.4 \%$, respectively. Of the 55 patients, $24(43.6 \%)$ showed objective response, eight (14.5\%) showed CR, $16(29.1 \%)$ showed PR, four $(7.3 \%)$ showed NC, $27(49.1 \%)$ showed PD. The median progression-free survival periods of CR/PR cases $(n=24)$
Table I Patients characteristics

\begin{tabular}{|c|c|}
\hline & $(n=55)$ \\
\hline \multicolumn{2}{|l|}{ Age (years) } \\
\hline Mean \pm s.d. & $58.2 \pm 9.4$ \\
\hline \multicolumn{2}{|l|}{ Gender } \\
\hline Male/female & $49 / 6$ \\
\hline \multicolumn{2}{|l|}{ Hepatitis virus } \\
\hline $\mathrm{HBsAg}+, \mathrm{HCVAb}-$ & 19 \\
\hline $\mathrm{HBsAg}-, \mathrm{HCVAb}+$ & 24 \\
\hline $\mathrm{HBsAg}+, \mathrm{HCVAb}+$ & 5 \\
\hline $\mathrm{HBsAg}-, \mathrm{HCVAb}-$ & 5 \\
\hline Unknown & 2 \\
\hline \multicolumn{2}{|l|}{ Granulocytes $\left(\mu l^{-1}\right)$} \\
\hline Mean \pm s.d. & $5310 \pm 1958$ \\
\hline \multicolumn{2}{|l|}{ Platelets $\left(\times 10^{4} \mu l^{-1}\right)$} \\
\hline Mean \pm s.d. & $15.3 \pm 6.7$ \\
\hline \multicolumn{2}{|l|}{ Serum albumin $\left(g d^{-1}\right)$} \\
\hline Mean \pm s.d. & $3.22 \pm 0.44$ \\
\hline \multicolumn{2}{|l|}{ Serum bilirubin ( $\left.m g d^{-1}\right)$} \\
\hline Mean \pm s.d. & $0.94 \pm 0.36$ \\
\hline \multicolumn{2}{|l|}{ Prothrombin time (s) } \\
\hline Mean \pm s.d. & $17.9 \pm 2.0$ \\
\hline \multicolumn{2}{|l|}{ Child-Pugh classification } \\
\hline A & 19 \\
\hline B & 31 \\
\hline C & 4 \\
\hline Unknown & I \\
\hline \multicolumn{2}{|l|}{$\operatorname{AFP}\left(n g \mathrm{ml}^{-1}\right)$} \\
\hline$<5^{\circ}$ & 2 \\
\hline$\geqslant 5$ & 52 \\
\hline Unknown & 1 \\
\hline \multicolumn{2}{|l|}{ PIVKA-II (mAU mll- $)$} \\
\hline$<40$ & 2 \\
\hline$\geqslant 40$ & 52 \\
\hline Unknown & 1 \\
\hline \multicolumn{2}{|l|}{ Tumour size $(\mathrm{cm})$} \\
\hline Mean \pm s.d. & $6.4 \pm 3.2$ \\
\hline
\end{tabular}

$\mathrm{HbsAg}=$ hepatitis B serum antigen; $\mathrm{HCVAb}=$ hepatitis C viral antibody; AFP = alpha-fetoprotein; PIVKA-\| = protein induced by vitamin $\mathrm{K}$ absence or antagonist-II.

was 12.0 months and that of NC/PD cases $(n=31)$ was 2.2 months. The 1-, 2-, and 3-year progression-free survival rates of CR/PR cases were $49.3,20.6$, and $20.6 \%$, respectively, and those of NC/PD cases were 0,0 , and $0 \%$, respectively. The median survival periods of CR/PR cases $(n=24)$ was 24.4 months and that of NC/PD cases $(n=31)$ was 5.4 months. The 1-, 2-, and 3-year survival rates of $\mathrm{CR} / \mathrm{PR}$ cases were $82.9,54.2$, and $30.9 \%$, respectively, and those of NC/PD cases were $13.1,0$, and $0 \%$, respectively. The time-toprogression survival and overall survival curves are shown in Figures 1 and 2 . There were significant difference in the time-toprogression survival and the overall survival between responders $(\mathrm{CR} / \mathrm{PR})$ and nonresponders $(\mathrm{NC} / \mathrm{PD})(P<0.0001)$.

\section{Adverse effects}

None of the patients developed side effects related to catheter insertion or subcutaneous implantation of the drug delivery 

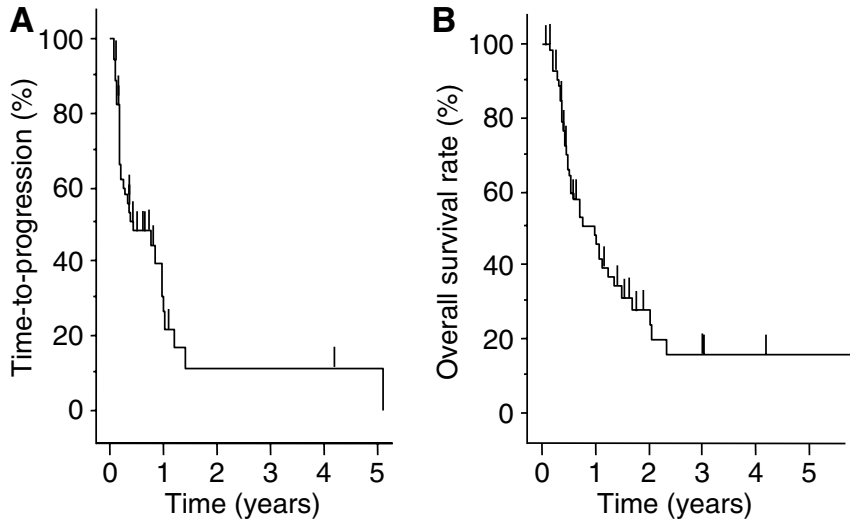

- All case $(n=55)$

Figure I Kaplan-Meyer analysis for efficiency of IFN- $\alpha / 5$-FU combination therapy. All 55 patients completed at least two courses of IFN- $\alpha / 5-F U$ combination therapy. (A) With respect to time-to-progression, the median progression-free survival period was 5.2 months and the $1-, 2-, 3-$, and 5 -year progression-free survival rates were $11.3,3.8,3.8$, and $1.9 \%$, respectively. (B) With respect to overall survival, the median overall survival period was 11 .8 months and the I-, 2-, 3-, and 5-year survival rates were $48.9,28.8,16.4$ and $16.4 \%$, respectively.
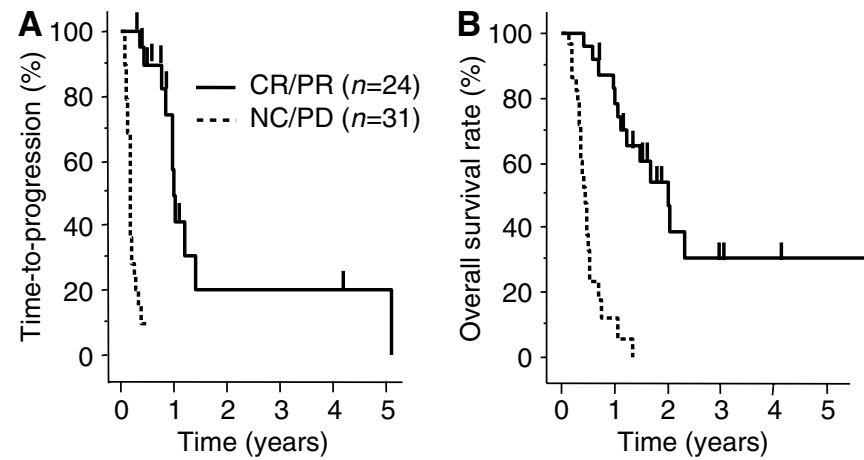

Figure 2 Kaplan-Meyer analysis for efficiency of IFN- $\alpha / 5-F U$ combination therapy. All 55 patients completed at least two courses of IFN- $\alpha / 5-F U$ combination therapy. A total of $24(43.6 \%)$ patients were assessed as objective responders; eight (I4.5\%) complete responders (CR), 16 (29.1\%) partial responders (PR), four (7.3\%) nonresponder (NC), and $27(49.1 \%)$ showed progressive disease (PD). With respect to time-to-progression and overall survival, there was a significant difference between objective responders (CR/PR) and nonresponders (NC/PD) $(P<0.000 \mathrm{I})$. (A) The median progression-free survival periods of CR/PR cases $(n=24)$ was 12.0 months and that of NC/PD cases $(n=31)$ was 2.2 months. The 1-, 2 -, and 3-year progression-free survival rates of CR/PR cases were $49.3,20.6$, and $20.6 \%$, respectively, and those of NC/PD cases were 0,0 , and $0 \%$, respectively. (B) The median survival period of CR/PR cases $(n=24)$ was 24.4 months and that of NC/PD cases $(n=31)$ was 5.4 months. The I-, $2-$, and 3-year survival rates of CR/PR cases were 82.9, 54.2, and $30.9 \%$, respectively, and those of NC/PD cases were $13.1,0$, and $0 \%$, respectively.

system. However, $14.6 \%$ of patients developed grade 3 leukopenia, thrombocytopenia, or anaemia, but drip transfusion of granulocyte colony-stimulating factors was not used during this study.

Nonhaematological toxicities included grade 1 or 2 fever $(100 \%$ of patients), chilling sense (100\%), flu-like syndrome (100\%), generalised fatigue $(25.4 \%)$, nausea $(5.5 \%)$, diarrhoea $(3.6 \%)$, gastric ulceration $(1.8 \%)$, skin reaction $(5.5 \%)$, and depression (3.6\%). The side effects are summarised in Table 2.
Table 2 Adverse effects

\begin{tabular}{lcccc}
\hline & \multicolumn{4}{c}{ Patients $(\mathbf{n}=\mathbf{5 5})$} \\
\cline { 2 - 5 } & Grade I & Grade 2 & Grade 3 & Grade 4 \\
\hline Haematological & & & & \\
Leukopenia & 0 & 1 & 3 & 0 \\
Anemia & 7 & 0 & 1 & 0 \\
Thrombocytopenia & 10 & 5 & 0 \\
Nonhaematological & & & & \\
Fever & 52 & 3 & 0 & 0 \\
Chilling sense & 52 & 0 & 0 & 0 \\
Nausea & 3 & 0 & 0 & 0 \\
Diarrhoea & 2 & 0 & 0 & 0 \\
Gastric ulcer & 0 & 1 & 0 & 0 \\
Flu-like syndrome & 55 & 0 & 0 & 0 \\
Skin reaction & 3 & 0 & 0 & 0 \\
General fatigue & 14 & 0 & 0 & 0 \\
Depression & 2 & 0 & 0 & \\
\hline
\end{tabular}

\section{Correlation between IFNAR2 immunostaining pattern and prognosis}

For each section, the intensity of IFNAR2 immunostaining was scored on a scale from 0 to 2 where 0 represented no or faint immunostaining (Figure 3A), 1: moderate (Figure 3B), and 2: strong staining (Figure 3C). IFN- $\alpha$ /type 2 interferon receptor expression was faint or undetectable in the vascular epithelium whereas epithelial cells of the bile ducts generally expressed moderate levels of IFNAR2 (Figure 3B, bottom). Accordingly, the latter level of staining was used as an inner control within the sample, which was designated arbitrarily as intensity level 1 . IFN$\alpha /$ type 2 interferon receptor expression was noted in $69.2 \%$ (nine out of 13) of cases. The median progression-free survival rate was 12.6 months for IFNAR2-positive cases, 1.7 months for IFNAR2-negative cases. The time-to-progression survival rates at 1,2 , and 3 years of IFNAR2-positive patients $(n=9)$ were significantly higher than the respective rates of IFNAR2-negative patients $(n=4) \quad(P=0.0002$, Figure $4 \mathrm{~A})$. The median overall survival rate was 24.4 months for IFNAR2-positive cases, 3.4 months for IFNAR2-negative cases. The overall survival rates at 1 , 2 , and 3 years of IFNAR2-positive patients $(n=9)(88.9,55.6$, and $22.2 \%$, respectively) were significantly higher than the respective rates $(0,0$, and $0 \%)$ of IFNAR2-negative patients $(n=4)$ $(P<0.0001$ each, Figure 4B).

\section{Clinical and pathological correlations}

Finally, we compared the responders (CR/PR) $(n=8)$ with the nonresponders (NC/PD) $(n=5)$ in terms of serum AFP (within normal range; $<5$ ), serum PIVKA-II (normal range; $<45$ ), ChildPugh score, OKUDA score, CLIP score, and IFNAR2 expression by univariate analysis (Table 3). Serum AFP, PIVKA-II, Child-Pugh score, OKUDA score, and CLIP score did not correlate with the response to combination therapy. On the other hand, IFNAR2 expression correlated significantly with the response to IFN- $\alpha / 5 \mathrm{FU}$ combination therapy $(P=0.0070)$. Thus, the expression level of IFNAR2 was the sole factor that influenced the response to the combination therapy. The correlation between IFNAR2 expression and response to therapy is shown in Figure 5.

\section{DISCUSSION}

In this study, we showed the beneficial effects of IFN- $\alpha / 5-F U$ combination therapy in patients with multiple lesions and tumour 

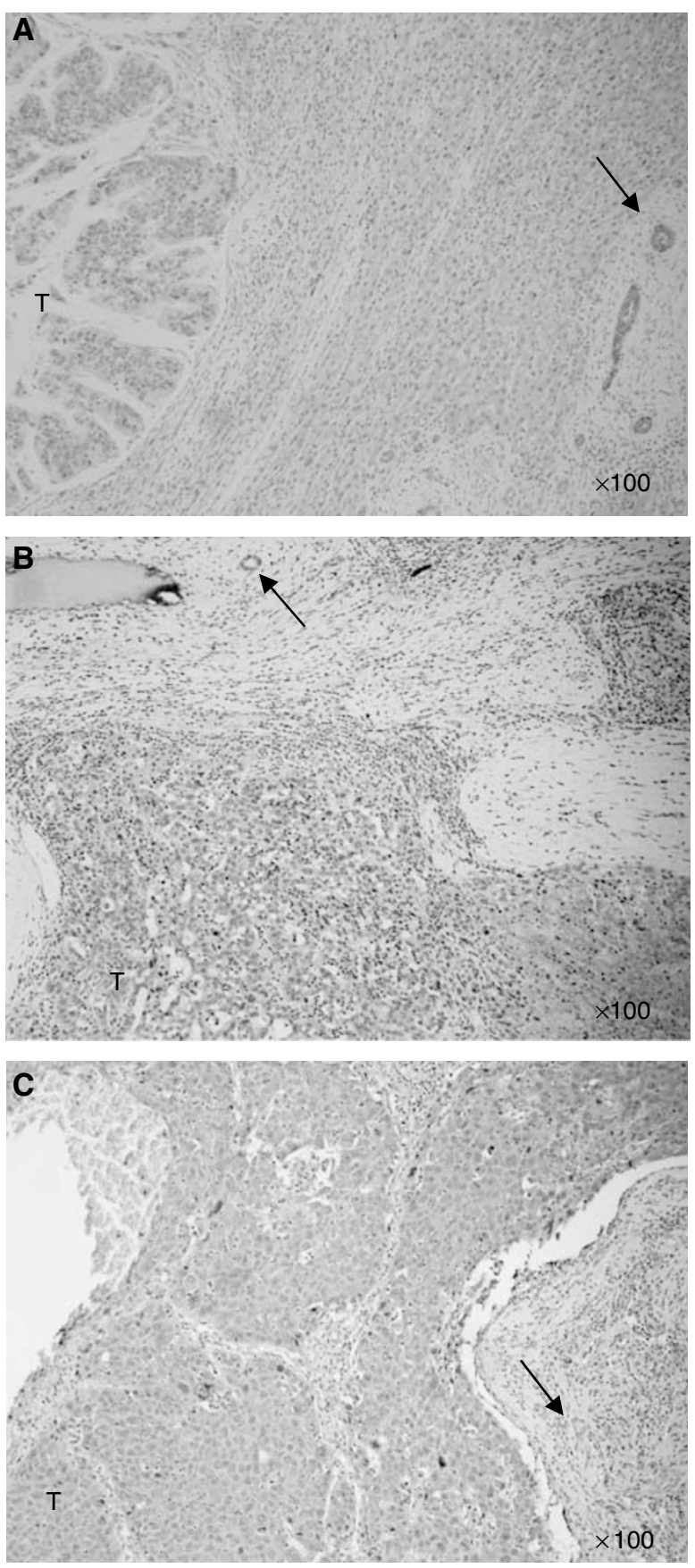

Figure 3 Immunohistochemical analysis of IFNAR2 expression in HCC tissues. The intensity of IFNAR2 was scored in a scale from 0 to 2: 0 representing no or faint staining $(\mathbf{A})$; I = moderate staining (B); and $2=$ strong staining $(\mathbf{C})$. The latter level of staining was used as an inner control (arrow) within the sample, which was designated arbitrarily as intensity I, because the epithelial cells of the bile ducts generally expressed moderate levels of IFNAR2

thrombi in the major branches of the portal vein ( $\mathrm{Vp} 3$ or 4$)$, as our second report on this treatment. The efficacy of such treatment was $43.6 \%$ in our patients with highly advanced HCC, which was almost similar to the previous report of patients with the same stage HCC (Urabe et al, 1998). The prognosis of such patients is extremely poor and survival is generally limited to a few months after diagnosis, despite multimodal therapies even in cases suitable
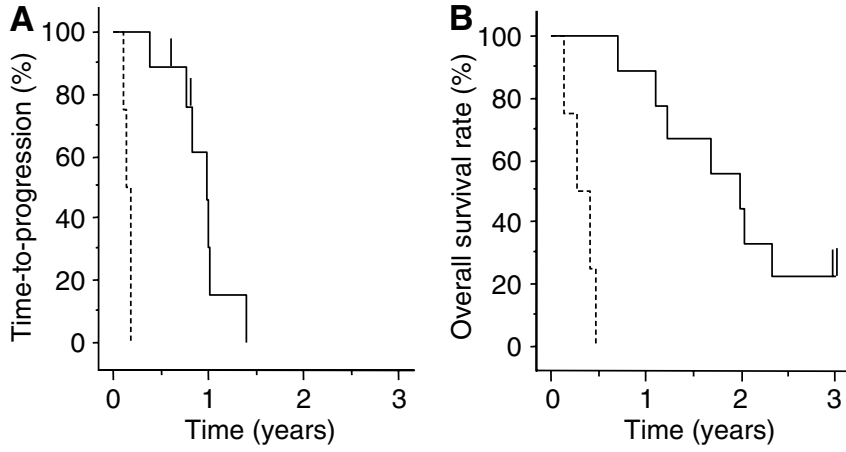

- IFNAR2 positive $(n=9)$

- . - IFNAR2 negative $(n=4)$

Figure 4 Kaplan-Meyer analysis for expression of IFNAR2. Immunohistochemical analysis was performed in 13 biopsy samples. The expression rate of IFNAR2 was $69.2 \%$ (nine out of I3). (A) The median progressionfree survival rate was 12.6 months for IFNAR2-positive cases and 1.7 months for IFNAR2-negative cases. The I-, 2-, and 3-year progression-free survival rates were $30.5,0$, and $0 \%$, respectively, for IFNAR2-positive cases, 0,0 , and $0 \%$, respectively, for IFNAR2-negative cases. There was a significant correlation between positive and negative cases $(P=0.0002)$.

(B) The median overall survival rate was 24.4 months for IFNAR2-positive cases and 3.4 months for IFNAR2-negative cases. The overall survival rates at I, 2, and 3 years of IFNAR2-positive patients $(n=9)(88.9,55.6$ and $22.2 \%$, respectively) were significantly higher than the rates $(0,0$, and $0 \%$, respectively) of IFNAR2-negative patients $(n=4)$. There was a significant difference between positive and negative cases $(P<0.000 \mathrm{I})$.

Table 3 Univariate analysis for efficiency of IFN- $\alpha / 5-F U$ combination therapy based on serum AFP, serum PIVKA-II, Child-Pugh score, CLIP score, and IFNAR2 expression

\begin{tabular}{|c|c|c|c|}
\hline & CR/PR $(n=24)$ & $\mathrm{NC} / \mathrm{PD}(n=3 \mathrm{I})$ & $P$-value \\
\hline \multicolumn{4}{|l|}{ Age } \\
\hline$<60$ & 12 & 15 & $>0.9999$ \\
\hline$\geqslant 60$ & 12 & 16 & \\
\hline \multicolumn{4}{|l|}{ Gender } \\
\hline Male & 21 & 28 & $>0.9999$ \\
\hline Female & 3 & 3 & \\
\hline \multicolumn{4}{|l|}{ Child-Pugh } \\
\hline$A$ & 8 & 11 & $>0.9999$ \\
\hline$B, C$ & 15 & 20 & \\
\hline \multicolumn{4}{|l|}{ AFP } \\
\hline$<400$ & 14 & 15 & 0.5919 \\
\hline$\geqslant 400$ & 10 & 15 & \\
\hline \multicolumn{4}{|l|}{ PIVKA-II } \\
\hline$<65$ & 3 & 1 & 0.3123 \\
\hline$\geqslant 65$ & 21 & 29 & \\
\hline \multicolumn{4}{|l|}{ Okuda } \\
\hline 1 & 19 & 23 & 0.3270 \\
\hline 2,3 & 3 & 8 & \\
\hline \multicolumn{4}{|l|}{ CLIP } \\
\hline $0,1,2,3$ & 12 & 13 & 0.7843 \\
\hline $4,5,6$ & 12 & 17 & \\
\hline \multicolumn{4}{|l|}{ IFNAR } \\
\hline Negative & 0 & 4 & 0.0070 \\
\hline Positive & 8 & I & \\
\hline
\end{tabular}

$\mathrm{CR}=$ complete response; $\mathrm{PR}=$ partial response; $\mathrm{NC}=$ no change; $\mathrm{PD}=$ progressive disease; AFP = alpha-fetoprotein; PIVKA-II = protein induced by vitamin $\mathrm{K}$ antagonists or absence. 


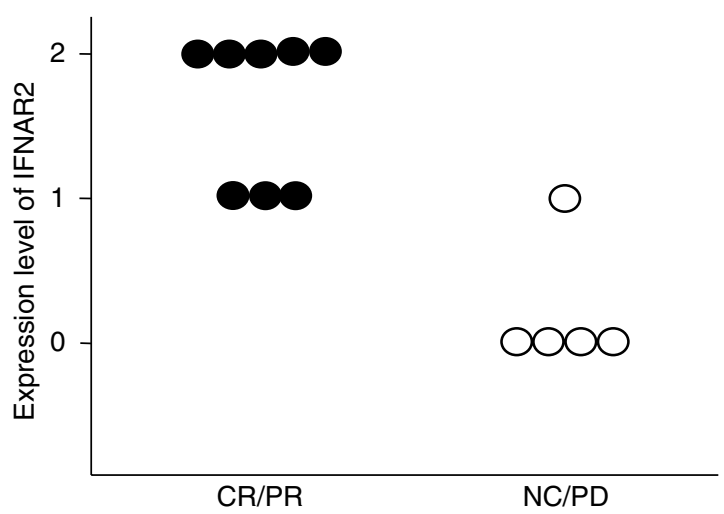

Figure 5 Correlation between IFNAR2 expression and efficiency of IFN- $\alpha / 5$-FU combination therapy. In eight objective responders, five cases showed intensity 2 , three cases intensity 1 , and none showed intensity 0 . In five nonresponders, one case showed intensity I, four cases intensity 0 , and none showed intensity 2 . There was a significant correlation between IFNAR2 expression and response to therapy.

for surgical resection (Poon et al, 2003). The combination treatment of IFN- $\alpha$ and 5-FU markedly decreased tumour size and levels of tumour markers with an encouraging response rate and prolonged survival time in the responders. Furthermore, the clinical response completely reflected the survival benefits, as shown in Figures 1 and 2. On the other hand, almost all nonresponders died within 6 months. No response to the combination therapy was seen in $56.4 \%$ (31 out of 55) of our patients in this study. To advance the effect of IFN- $\alpha / 5-F U$ combination therapy and to increase the response rate, it is necessary to investigate the mechanism of IFN- $\alpha / 5-\mathrm{FU}$ combination therapy.

Several mechanisms for the anticancer effects of IFN- $\alpha$, with or without 5-FU, have been proposed. In general, both agents have antitumour properties, even when used alone. These effects can be direct and/or indirect (immunological) antitumour effects. The direct antitumour effects include cell damage (Grander et al, 1993), upregulation of cancer antigen (Guadagni et al, 1989), and delayed action on the cell cycle (Kimchi, 1992). On the other hand, the indirect antitumour actions include activation of natural killer cells (Ortaldo et al, 1983), T cell system (Brinkmann et al, 1993), and macrophages (Uno et al, 1985). It is also possible that both IFN- $\alpha$ and 5-FU reinforce the antitumour action of each other or have additive effects. In vitro experiments showed that IFN- $\alpha$ induces cyclin-dependent kinase inhibitors involved in G1/G0 arrest (Sangfelt et al, 1999). Interferon- $\alpha$ may also exert its antitumour effect indirectly via the immune system since IFN- $\alpha$ is known to augment T-cell cytotoxicity (Lindahl et al, 1972; Trinchieri et al, 1978). Recently, we reported that the modulation of tumour necrosis factor-related apoptosis-inducing ligand (TRAIL) receptor-mediated cytotoxic pathway could partially contribute to the anti-HCC effect of IFN- $\alpha / 5$-FU combination therapy (Yamamoto et al, 2004). In addition, several experimental studies demonstrated that IFN- $\alpha$ enhanced the cytotoxic effect of 5-FU in various cultured malignant cells (Wadler and Schwartz, 1990; Schwartz et al, 1992). The upregulation of 5-FU activities combined with IFN- $\alpha$ was also shown by our laboratories (Damdinsuren et al, 2003).

Moreover, IFN- $\alpha$ suppressed the proliferation of all IFNAR2positive HCC cell lines in vitro through mechanisms related to apoptosis or inhibition of cell cycle (Yano et al, 1999). The importance of IFNAR2 expression for the anticancer effect of IFN- $\alpha / 5-F U$ was shown in such situation in our previous report (Eguchi et al, 2000). These findings suggest that the antineoplastic effects of IFN- $\alpha$ are likely to be mediated through its high-affinity membrane type I receptor, IFNAR2 (Darnell et al, 1994). In this regard, IFNAR2 expression in HCC tissues may be a useful predictor of response to such therapy and thus distinguish between responders and nonresponders to IFN- $\alpha / 5$-FU combination therapy.

We previously validated the suitability of IFNAR2 antibody (OCT4813) used in the present study, by the agreement between the results of immunohistochemistry and Western blot analysis; when expression of IFNAR2 protein was examined after cell fractionation in a patient positive for IFNAR2, the long and short forms of IFNAR2 were predominant in the cell membrane fraction while the soluble form was observed only in the cytosol fraction (Kondo et al, 2000). This result demonstrated that the immunohistochemically evident expression of IFNAR2 correlated with the expression of the active form of IFNAR2 (Yatsuhashi et al, 1999). The reliability of this antibody was also established in two other reports (Takayama et al, 2000; Fujiwara et al, 2003). Based on these results, we investigated the relationship between IFNAR2 expression and the effect of IFN- $\alpha / 5$-FU combination therapy using immunohistochemical analysis. Our results showed good correlation between the effect of such therapy and expression level of IFNAR2.

Several markers for prediction of tumour recurrence and prognosis have been identified. Levy and Sherman (2002) reported that the CLIP classification for HCC is easier to implement and more accurate than the OKUDA classification. In addition, Koike et al (2001) suggested that serum PIVKA-II level is the most useful predisposing clinical parameter for the development of portal vein invasion. To investigate the role of these clinical parameters, AFP, PIVKA-II, OKUDA score, and CLIP score were used in the present study to assess the clinical effects of IFN- $\alpha / 5-F U$ combination therapy. The results showed that the expression of IFNAR2 was the only significant predictor of clinical outcome of IFN- $\alpha / 5-F U$ combination therapy; no significant correlation was found with other factors, including serum AFP, serum PIVKA-II, Child-Pugh score, Okuda Score, and CLIP score. Moreover, survival analysis showed the significant role of IFNAR2 expression on prognosis; IFNAR2-positive cases had better prognosis than negative cases. These results suggest that the expression of IFNAR2 could be a potentially useful predictor of the response to IFN- $\alpha / 5$ FU combination therapy. In our recent report using microarray analysis, several genes concerned with IFN signalling transduction were found useful for molecular prediction of response to IFN- $\alpha / 5$ FU combination therapy in advanced HCC (Kurokawa et al, 2004).

Two issues should be discussed in relation to our results. First, IFN- $\alpha / 5$-FU combination therapy had no effect in IFNAR2negative cases. Upregulation of IFNAR2 may be considered in order to induce a better response to the therapy in such cases. This proposition is based on the results of early studies, in addition to those of the present study. For example, Wagner et al (2004) showed that LOX, MDA231, MT1, and HT1080 cell lines transfected with IFNAR2c demonstrated a marked increase in their IFN-dependent antiproliferative response. Applying this method to HCC cells, IFNAR1/2 transfection might lead to overexpression of IFNAR2 and IFN- $\alpha$-induced cell apoptosis. One recent study involving in vitro experiments showed that IFNAR2 gene transfer is effective in augmenting the biological activity of IFN- $\alpha / 5$-FU combination therapy in human HCC (Kondo et al, 2005). Thus, IFNAR2 gene transfection might enhance the response to IFN- $\alpha / 5-\mathrm{FU}$ combination therapy in IFNAR2-negative patients.

Second, not all IFNAR2-positive cases benefited from IFN- $\alpha / 5$ FU combination therapy. In such patients, increasing the doses or modifying the combination therapy (e.g. addition of other antitumour agents) might increase the response rate. Other parameters, apart from the expression of IFNAR2, might be important and necessary for the response to IFN- $\alpha / 5-\mathrm{FU}$ 
combination therapy. A recent report showed that transcription of the $\mathrm{p} 53$ gene is induced by IFN- $\alpha$, accompanied by an increase in p53 protein level (Takaoka et al, 2003). The study suggested that p53 gene might be an important predictor of IFN- $\alpha$ therapy for HCV liver cirrhosis and HCC. In addition to IFNAR2 immunohistochemistry, p53 sequence analysis may identify other factors that could predict the response to IFN- $\alpha / 5-\mathrm{FU}$ combination therapy. In this regard, Yano et al (1999) used HCC cell lines and showed that normal p53 gene expression is not necessary for IFN- $\alpha$-induced apoptosis. Thus, further studies are required to determine the importance of p53 mutation on the response to IFN- $\alpha / 5$-FU combination therapy.

In conclusion, we demonstrated the efficacy of IFN- $\alpha / 5-F U$ combination therapy for patients of advanced HCC with tumour thrombi in major branches of the portal vein. We also showed that the clinical response to such therapy correlated significantly with the expression of IFNAR2 in HCC.

\section{ACKNOWLEDGEMENTS}

We thank Dr Yasukazu Ohmoto, from the First Institute of New Drug Research, and Otsuka Pharmaceutical Co., Ltd, for providing anti-human IFNAR2 antibody (OCT4813). This work was supported by a Grant-in-Aid for cancer research from the Ministry of Health and Welfare of Japan, and by an Award from The Osaka Medical Research Foundation for Incurable Diseases.

\section{REFERENCES}

Ando E, Yamashita F, Tanaka M, Tanikawa K (1997) A novel chemotherapy for advanced hepatocellular carcinoma with tumor thrombosis of the main trunk of the portal vein. Cancer 79: $1890-1896$

Asahara T, Itamoto T, Katayama K, Nakahara H, Hino H, Yano M, Ono E, Dohl K, Nakanishi T, Kitamoto M, Azuma K, Itoh K, Shimamoto F (1999) Hepatic resection with tumor thrombectomy for hepatocellular carcinoma with tumor thrombi in the major vasculature. Hepatogastroenterology 46: $1862-1869$

Brinkmann V, Geiger T, Alkan S, Heusser CH (1993) Interferon alpha increases the frequency of interferon gamma-producing human CD4+ T cells. J Exp Med 178: 1655 - 1663

Cancer of Liver Italian Program (CLIP) investigators (1998) A new prognostic system for hepatocellular carcinoma: a retrospective study of 435 patients. Hepatology 28: $751-755$

Chen SC, Hsieh MY, Chuang WL, Wang LY, Chang WY (1994) Development of portal vein invasion and its outcome in hepatocellular carcinoma treated by transcatheter arterial chemo-embolization. J Gastroenterol Hepatol 9: 1-6

Chung YH, Song IH, Song BC, Lee GC, Koh MS, Yoon HK, Lee YS, Sung KB, Suh DJ (2000) Combined therapy consisting of intraarterial cisplatin infusion and systemic interferon - for hepatocellular carcinoma patients with major portal vein thrombosis or distant metastasis. Cancer 88: 1986-1991

Ciaparrone M, Yamamoto H, Yao Y, Sgambato A, Cattoretti G, Tomita N, Monden T, Rotterdam H, Weinstein IB (1998) Localization and expression of p27KIP1 in multistage colorectal carcinogenesis. Cancer Res 58: $114-122$

Damdinsuren B, Nagano H, Sakon M, Kondo M, Yamamoto T, Umeshita K, Dono K, Nakamori S, Monden M (2003) Interferon- $\beta$ is more potent than interferon- $\alpha$ in human hepatocellular carcinoma cell growth when used alone and in combination with anticancer drugs. Ann Surg Oncol 10: $1184-1190$

Darnell Jr JE, Kerr IM, Stark GR (1994) Jak-STAT pathways and transcriptional activation in response to IFNs and other extracellular signaling proteins. Science 3: $1415-1421$

Doci R, Bignami P, Bozzetti F, Bonfanti G, Audisio R, Colombo M, Gennari L (1988) Intrahepatic chemotherapy for unresectable hepatocellular carcinoma. Cancer 61: 1983-1987

Eguchi H, Nagano H, Yamamoto H, Miyamoto A, Kondo M, Dono K, Nakamori S, Umeshita K, Sakon M, Monden M (2000) Augmentation of anti-tumor activity of 5-FU by IFN- $\alpha$ is associated with up-regulation of p27Kip1 in human hepatocellular carcinoma cells. Clin Cancer Res 6: $2881-2890$

Fujiwara D, Hino K, Yamaguchi Y, Ren F, Satoh Y, Korenaga M, Okuda M, Okita K (2003) Hepatic expression of type I interferon receptor of predicting response to interferon therapy in chronic hepatitis $\mathrm{C}$ patients: a comparison of immuno-histochemical methods vs competitive polymerase chain reaction assay. Hepatol Res 25: 377-384

Furuse J, Iwasaki M, Yoshino M, Konishi M, Kawano N, Kinoshita T, Ryu M, Satake M, Moriyama N (1997) Hepatocellular carcinoma with portal vein tumor thrombus: embolization of arterioportal shunts. Radiology 204: $787-790$

Grander D, Xu B, Einhorn S (1993) Cytotoxic effect of interferon on primary malignant tumour cells. Studies in various malignancies. Eur J Cancer 29A: $1940-1943$
Guadagni F, Schlom J, Johnston WW, Szpak CA, Goldstein D, Smalley R, Simpson JF, Borden EC, Pestka S, Greiner JW (1989) Selective interferoninduced enhancement of tumor-associated antigens on a spectrum of freshly isolated human adenocarcinoma cells. J Natl Cancer Inst 81: $502-512$

Kimchi A (1992) Cytokine triggered molecular pathways that control cell cycle arrest. J Cell Biochem 50: $1-9$

Koike Y, Shiratori Y, Sato S, Obi S, Teratani T, Imamura M, Yoshida H, Shiina S, Omata M (2001) Des-gamma-carboxy prothrombin as a useful predisposing factors for the development of portal venous invasion in patients with hepatocellular carcinoma: a prospective analysis of 227 patients. Cancer 91: $561-569$

Kondo M, Nagano H, Sakon M, Yamamoto H, Morimoto O, Arai I, Miyamoto A, Eguchi H, Dono K, Nakamori S, Umeshita K, Wakasa K, Ohmoto Y, Monden M (2000) Expression of interferon $\alpha / \beta$ receptor in human hepatocellular carcinoma. Int J Oncol 17: 83-88

Kondo M, Nagano H, Wada H, Damdinsuren B, Yamamoto H, Hiraoka N, Eguchi H, Miyamoto A, Yamamoto T, Ota H, Nakamura M, Marubashi S, Dono K, Umeshita K, Nakamori S, Sakon M, Monden M (2005) Combination of interferon alpha and 5-fluorouracil induces apoptosis through interferon alpha/beta receptor in human hepatocellular carcinoma cells. Clin Cancer Res 11: $1277-1286$

Kurokawa Y, Matoba M, Nagano H, Sakon M, Takemasa I, Nakamori S, Dono K, Umeshita K, Ueno N, Ishii S, Kato K, Monden M (2004) Molecular prediction of response to 5-fluorouracil and interferon- $\alpha$ combination chemotherapy in advanced hepatocellular carcinoma. Clin Cancer Res 10: 6029-6038

Lee HS, Kim JS, Choi IJ, Chung JW, Park JH, Kim CY (1997) The safety and efficacy of transcatheter arterial chemoembolization in the treatment of patients with hepatocellular carcinoma and main portal vein obstruction: a prospective controlled study. Cancer 79: 2087 -2094

Leung TW, Patt YZ, Lau WY, Ho SK, Yu SC, Chan AT, Mok TS, Yeo W, Liew CT, Leung NW, Tang AM, Johnson PJ (1999) Complete pathological remission is possible with systemic combination chemotherapy for inoperable hepatocellular carcinoma. Clin Cancer Res 5: 1676-1681

Levy I, Sherman M, the Liver Cancer Group of the University of Toronto (2002) Staging of hepatocellular carcinoma: assessment of the CLIP, Okuda, and Child-Pugh staging systems in a cohort of 257 patients in Toronto. Gut 50: $881-885$

Lindahl P, Leary R, Gresser I (1972) Enhancement by interferon of the specific cytotoxicity of sensitized lymphocytes. Proc Natl Acad Sci USA 69: $721-725$

Miyamoto A, Umeshita K, Sakon M, Nagano H, Eguchi H, Kishimoto S, Dono K, Nakamori S, Gotoh M, Monden M (2000) Advanced hepatocellular carcinoma with distant metastases, successfully treated by a combination therapy with (-interferon and oral tegaful/uracil. $J$ Gastroenterol Hepatol 15: $1447-1451$

Novick D, Cohen B, Rubinstein M (1994) The human interferon alpha/beta receptor: characterization and molecular cloning. Cell 77: $391-400$

Oken MM, Creech RH, Tormey DC, Horton J, Davis TE, McFadden ET, Carbone PP (1982) Toxicity and response criteria of the Eastern Cooperative Oncology Group. Am J Clin Oncol 5: 649-655

Ortaldo JR, Mantovani A, Hobbs D, Rubinstein M, Pestka S, Herberman RB (1983) Effects of several species of human leukocyte interferon 
on cytotoxic activity of $\mathrm{NK}$ cells and monocytes. Int J Cancer 31: $285-289$

Patt YZ, Yoffe B, Charnsangavej C, Pazdur R, Fischer H, Cleary K, Roh M, Smith R, Noonan CA, Levin B (1993) Low serum alpha-fetoprotein level in patients with hepatocellular carcinoma as a predictor of response to 5-FU and interferon-alpha- 2b. Cancer 72: 2574-2582

Poon RT, Fan ST, Ng IO, Wong J (2003) Prognosis after hepatic resection for Stage IVA hepatocellular carcinoma: a need for reclassification. Ann Surg 237: $376-383$

Sakon M, Nagano H, Dono K, Nakamori S, Umeshita K, Yamada A, Kawata S, Imai Y, Iijima S, Monden M (2002) Combined intraarterial 5 fuluorouracil and subcutaneous interferon- $\alpha$ therapy for advanced hepatocellular carcinoma with tumor thrombi in the major portal branches. Cancer 94: 435-442

Sangfelt O, Erickson S, Castro J, Heiden T, Gustafsson A, Einhorn S, Grander D (1999) Molecular mechanisms underlying interferon-alphainduced G0/G1 arrest: CKI-mediated regulation of G1 Cdk-complexes and activation of pocket proteins. Oncogene 18: 2798-2810

Schwartz EL, Hoffman M, O'Conneor CJ, Wadler S (1992) Stimulation of 5 -Fluorouracil metabolic activation by interferon- $\alpha$ in human colon carcinoma cells. Biochem Biophys Res Commun 323: 425-428

Takaoka A, Hayakawa S, Yanai H, Stoiben D, Negishi H, Kikuchi H, Sasaki S, Imai K, Shibue T, Honda K, Taniguchi T (2003) Integration of interferon- $\alpha /$ signaling to $\mathrm{p} 53$ responses in tumour suppression and antiviral defence. Nature 424: 516-523

Takayama A, Yano H, Ogasawara S, Higaki K, Kojiro M (2000) Expression of $\mathrm{Hu}$ - IFN- $\alpha \mathrm{R} 2$ chain of type I interferon receptor in human hepatocellular carcinoma and non-cancerous tissues. Int J Mol Med 6: $621-627$

Tanaka A, Morimoto T, Yamaoka Y (1996) Implications of surgical treatment for advanced hepatocellular carcinoma with tumor thrombi in the portal vein. Hepatogastroenterology 43: 637-643

Toyoda H, Nakano S, Kumada T, Takeda I, Sugiyama K, Osada T, Kiriyama S, Suga T, Takahashi M (1995) The efficacy of continuous local arterial infusion of 5-fluorouracil and cisplatin through an implanted reservoir for severe advanced hepatocellular carcinoma. Oncology 52: 295-299

Trinchieri G, Santoli D, Koprowski H (1978) Spontaneous cell-mediated cytotoxicity in humans; role of interferon and immunoglobulins. Immunol 120: 1849-1855
Uno K, Shimizu S, Ido M, Naito K, Inaba K, Oku T, Kishida T, Muramatsu S (1985) Direct and indirect effects of interferon on in vivo murine tumor cell growth. Cancer Res 45: $1320-1327$

Urabe T, Kaneko S, Matsushita E, Unoura M, Kobayashi K (1998) Clinical pilot study of intrahepatic arterial chemotherapy with methotrexate, 5-fluorouracil, cisplatin and subcutaneous interferon-alpha-2b for patients with locally advanced hepatocellular carcinoma. Oncology 55: $39-47$

Wadler S, Schwartz EL (1990) Antineoplastic activity of the combination of interferon and cytotoxic agents against experimental and human malignancies: a review. Cancer Res 50: $3473-3486$

Wagner TC, Velichko S, Chesney SK, Biroc S, Harde D, Vogel D, Croze E (2004) Interferon receptor expression regulates the antiproliferative effects of interferon on cancer cells and solid tumors. Int J Cancer 111: $32-42$

WHO handbook for reporting results of cancer treatment (1979) World Health Organization Offset Publication No 48. Geneva: Switzerland

Yamakado K, Tanaka N, Nakatsuka A, Matsumura K, Takase K, Takeda K (1999) Clinical efficacy of portal vein stent placement in patients with hepatocellular carcinoma invading the main portal vein. J Hepatol 30: $660-668$

Yamamoto T, Nagano H, Sakon M, Wada H, Eguchi H, Kondo M, Damdinsuren B, Ota H, Nakamura M, Wada H, Yamamoto H, Marubash S, Miyamoto A, Dono K, Umeshita K, Nakamori S, Yagita H, Monden M (2004) Partial contribution of TRAIL/TRAIL receptor pathway to antitumor effects of IFN- $\alpha / 5-\mathrm{FU}$ against hepatocellular carcinoma. Clin Cancer Res 10: 7884-7895

Yano H, Iemura A, Haramaki M, Ogasawara S, Takayama A, Akiba J, Kojiro M (1999) Interferon alfa receptor expression and growth inhibition by interferon alfa in human liver cancer cell lines. Hepatology 29: 1708 1717

Yatsuhashi H, Fujino T, Matsumoto T, Inoue O, Koga M, Yano M (1999) Immunohistochemical analysis of hepatic interferon alpha-beta receptor level: relationship between receptor expression and response to interferon therapy in patients with chronic hepatitis C. J Hepatol 30: $995-1003$

Yen FS, Wu JC, Kuo BI, Chiang JH, Chen TZ, Lee SD (1995) Transcatheter arterial embolization for hepatocellular carcinoma with portal vein thrombosis. J Gastroenterol Hepatol 10: 237-240 